\title{
Gunshot Injury to the Groin: Management of Patients with Life-Threatening Condition Gunshot Injury to the Groin
}

\author{
Serkan B. DEŞER ${ }^{1}$, Mustafa K. DEMIRAĞ ${ }^{1}$
}

${ }^{1}$ Department of Cardiovascular Surgery, Faculty of Medicine, 19 Mayıs University, Samsun, Turkey.

Dear Editor,

Gunshot injuries have become increasingly common in Turkey. Patients with gunshot arterial injuries to the groin admitted to the emergency department present with rapidly expanding hematoma, absent distal pulse, bruit over the artery, ischemic limb, unrecordable blood pressure, confused status, tachycardia, tachypnea, and pulsatile external bleeding (1). Prompt restoration of the circulation is mandatory to avoid death and ischemia. Although vascular injuries are not uncommon, femoral vascular injuries are the most common, accounting for approximately $70 \%$ of all peripheral vascular injuries. Vascular injuries were common during war, constituting 2\%-5\% of all injuries (2). Amputation rate was $50 \%$ in the World War $I I$ and reduced to less than $10 \%$ during the Vietnam War (3).

This study aimed to share the management of a case with left groin injury due to a close-distance gunshot. The 16-yearold male patient was admitted to the clinic as intubated. He was in hypovolemic shock, and mechanical cardiopulmonary resuscitation was performed. He had an $8 \times 8 \mathrm{~cm}$ wound defect on his left groin due to a close gunshot with massive bleeding. Under general anesthesia, median laparotomies via midline incision extended to the left groin were meticulously performed. Reversed saphenous vein was used as the graft between the edges of the femoral artery and vein (Fig. 1).

The signs of vascular injury are pulsatile hemorrhage, expanding hematoma, palpable thrill, audible bruit, or pulseless limb. Surgical indications of vascular injury include reduced and unequal pulses, a nonpulsatile hematoma, and history of hemorrhage. Various surgical techniques are available for repairing the vessel injury, including primary suturing, lateral arteriorrhaphy, patch angioplasty, end-to-end anastomosis, and interposition by a synthetic (Dacron/PTFE) or venous graft. Arterial ligation is only indicated when the patient is hemodynamically unstable, with severe blood loss and long duration of surgery. Also, venous repair can be carried out using simple venorrhaphy whenever possible (4).

In conclusion, prompt intervention and diagnosis are essential. Surgical repair remains the gold standard in managing vascular injuries.

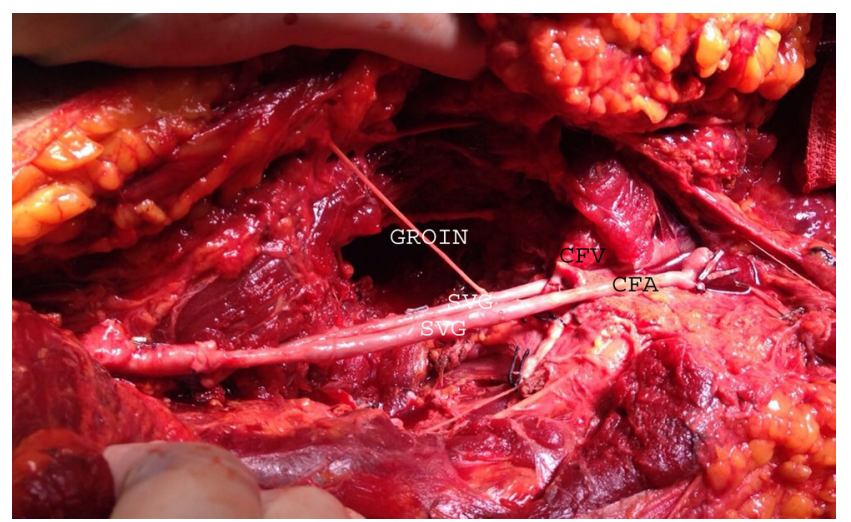

FIGURE 1: A Intraoperative image of the injured vessels repaired with saphenous vein grafts

(SVG: Saphenous vein graft, CFV: Common femoral vein, and CFA: Common femoral artery). 


\section{REFERENCES}

1. Rozyczki GS, Tremblay LN, Feliciano DV, McClelland WB. Blunt vascular trauma in the extremity: diagnosis, management, and outcome. J Trauma 2003;55(5):814-24.

2. Starnes BW, Beekley AC, Sebesta JA, Adersen CA, Rush RM Jr. Extremity vascular injuries on the battlefield: tips for surgeons deploying to war. J Trauma 2006;60(2):432-42.

3. Oliver JC, Bekker W, Edu S, Nicol AJ, Navsaria PH. A Ten Year Review of Civilian Iliac Vessel Injuries from a Single Trauma Centre. European Journal of Vascular and Endovascular Surgery 2012;44:199-202.

4. Babu YPR, Fahad S, Atreya A, Bakkannavar S, Kumar GNP, Acharya J. An unusual case of fatal transection of femoral vessels. Egyptian Journal of Forensic Sciences 2016;6:307-309. 